\title{
Power Control for High Speed Wind by Using the Backstepping Strategy
}

\author{
A. Mechtar, K. Kemih, A. Kalfat \\ L2EI Laboratory, Jijel University \\ Jijel, Algeria \\ e-mail:k.kemih@gmail.com
}

\author{
M. Ghanes \\ ECS-Lab, ENSEA \\ Cergy-Pontoise, France \\ e-mail: ghanes@ensea.fr
}

\begin{abstract}
This paper proposes a new approach based on the association of backstepping control with genetic algorithm for power generation control of variable speed wind turbine under the effect of high wind. The Genetic algorithms are used to estimate the values of the pitch angel and Tip speed ratio and the backstepping control is used to calculate electromagnetic torque applied to the system to enslave the speed of the generator. The simulation results demonstrate the effectiveness of the proposed control strategy.
\end{abstract}

Keywords-genetic algorithm, Backstepping control, wind turbines, pitch angle.

\section{INTRODUCTION}

Recently, the majority of wind turbine used in wind farms is based on doubly fed induction generator (DFIG) due to some advantages like, the variable speed generation, the improvement of the power quality....[1-2]. Many previous research works have treated the problem of controlling the turbine in high wind speed; Bianchi et al. [3] have proposed the use of the optimal control for regulate the power, Boukhezzar et al. [4] have used a multivariable control strategy by combining a nonlinear dynamic state feedback torque control strategy with a linear control strategy for the blade pitch angle, in the other side, Serdar al. [5] proposed the use of the artificial neural network, Bououden et al [6] the LMI design with predictive control and Camblong [7] the Digital robust control. The aim of this paper is to establish a control law that maintains the power to its nominal value in high wind speed. For this, we use the nonlinear backstepping control associated with genetic algorithm; this combination can not only increase the performance of the electrical power but also optimize the pitch angle of the blades. In the first part of our work, we describe the model of the turbine, then, we present the control strategy of wind turbine system. With the backstepping technique, we develop the command (Electromagnetic torque) applied to the system to enslave the speed of the generator and to further improve the performance of the proposed control, we use the genetic algorithm to optimize the pitch angle of the blades.

\section{Modelling OF THE TURBINE}

As is shown in fig.1 [6], the mechanical part of the wind turbine is constituted of: a rotor which is generally composed of three blades, a speed multiplier whose its role is to adjust the speed of the rotor to that of the electric generator. The generator only represents the electrical part. The energy contained in the wind depends on the following parameters: rotor radius $(R)$, the wind speed $(v)$, and the air density $(\rho)$, this energy is given by [9]:

$$
P_{v}=\frac{1}{2} \rho S v^{3}=\frac{1}{2} \rho \pi R^{2} v^{3}
$$

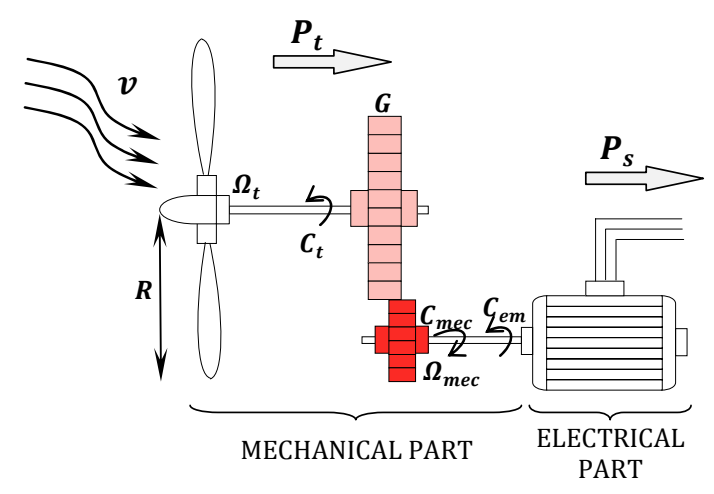

Figure.1. Configuration of a wind turbine.

[10] give the wind power captured by the rotor: $P_{t}=$ $C_{p}\left(\frac{1}{2} \rho \pi R^{2} v^{3}\right)(2)$, where, the power coefficient $\left(C_{p}\right)$ represents the aerodynamic efficiency of the turbine and depends on the specific speed $(\lambda)$ and the pitch angle $(\beta)$ [11]. It is given by:

$$
\begin{gathered}
C_{p}(\lambda, \beta)=c_{1}\left(c_{2}\left(\frac{1}{\lambda+0.08 \beta}-\frac{0.035}{\beta^{3}+1}\right)-c_{3} \beta-\right. \\
\left.c_{4}\right) e^{-\left(\frac{1}{\lambda+0.08 \beta}-\frac{0.035}{\beta^{3}+1}\right)}+c_{6} \lambda \quad(3), \text { with, } c_{1}= \\
0.5109, c_{2}=116, c_{3}=0.4, c_{4}=5, c_{5}=21, c_{6}= \\
0.0068 .
\end{gathered}
$$

Where, $\lambda$ represents the ratio between the blades linear speed and the wind speed, it is given by: $\lambda=\frac{R \Omega_{t}}{v}(4) . \Omega_{t}$, is the mechanical angular speed of the turbine $(\mathrm{rad} / \mathrm{sec})$. The mechanical torque available on the axis of the turbine is given by: 


$$
C_{t}=\frac{P_{t}}{\Omega_{t}}=\frac{0.5 C_{p} \rho \pi R^{2} v^{3}}{\Omega_{t}}
$$

The mechanical torque (respectively, the mechanical angular speed) on the axis of the generator are given by:

$$
\left\{\begin{array}{l}
C_{\text {mec }}=\frac{1}{G} C_{t} \\
\Omega_{\text {mec }}=G \Omega_{t}
\end{array}\right.
$$

where, $\boldsymbol{G}$ is the multiplication ratio.

The model of the generator shaft is given by the following expression [12]:

$$
J \dot{\Omega}_{m e c}=C_{m e c}-C_{e m}-f \Omega_{m e c} \quad(7),
$$

with, $J$, the total inertia of the rotating parts $\left(K g \cdot \mathrm{m}^{2}\right)$, $f$, the coefficient of viscous damping. $C_{e m}$, the electromagnetic torque of the generator

$$
\text { (N.m). } J=\frac{J_{\text {Turbine }}}{G^{2}}+J_{\text {Generator }}
$$

According to (4), (5) and (6)

where,

$$
: C_{T}=K_{1} K_{2} \Omega_{m e c}^{2}-C_{e m}
$$

$$
\begin{aligned}
& K_{1}=\frac{0.5 \rho \pi R^{5}}{G^{3}} \\
& K_{2}=\frac{c_{p}}{\lambda^{3}}
\end{aligned}
$$

Then, the dynamic of the system is given by:

$$
\dot{\Omega}_{m e c}=\frac{1}{J}\left(K_{1} K_{2} \Omega_{m e c}^{2}-f \Omega_{m e c}-C_{e m}\right)
$$

\section{BACKSTEPPING CONTROL}

The idea of backstepping control [13] consists in calculating a control law in order to guarantee that the derivative of Lyapunov function (definite positive) is always negative. First, we calculate the first virtual command from the tracking error $e_{1}=y-y_{r e f}$, this command will be used in the second step as a reference signal for the next state. We repeat the operation until reaching the $n^{\text {th }}$ step where we obtain a command that will be applied to the system. In our work, the state vector contains only one variable (Eq.12). So, the synthesis of the backstepping control law is composed of a single step.

We have as a reference, $y_{r e f}=\Omega_{m e c}^{r e f}$. The tracking error is given by: $\varepsilon_{\Omega}=\Omega_{\text {mec }}-\Omega_{\text {mec }}^{\text {ref }}$ (13).

The time derivative is written: $\dot{\varepsilon}_{\Omega}=\dot{\Omega}_{m e c}-$ $\dot{\Omega}_{m e c}^{r e f}=\frac{K_{1} K_{2}}{J} \Omega_{m e c}^{2}-\frac{f}{J} \Omega_{m e c}-\frac{1}{J} C_{e m}-\dot{\Omega}_{m e c}^{r e f}(14)$.

The Lyapunov function is given by: $v\left(\varepsilon_{\Omega}\right)=\frac{1}{2} \varepsilon_{\Omega}^{2}$ (15). If this function is always positive definite and its derivative is always negative, then the error will be stable and will tend towards zero. The derivative of the error is given by: $\quad \dot{v}\left(\varepsilon_{\Omega}\right)=\varepsilon_{\Omega} \dot{\varepsilon}_{\Omega}=\varepsilon_{\Omega}\left(\frac{K_{1} K_{2}}{J} \Omega_{m e c}^{2}-\right.$ $\left.\frac{f}{J} \Omega_{m e c}-\frac{1}{J} C_{e m}-\dot{\Omega}_{m e c}^{r e f}\right)(16)$. A good choice of $C_{e m}$ would render $\dot{v}\left(\varepsilon_{\Omega}\right)$ negative and ensure the stability of the origin of (14). Then: $\frac{K_{1} K_{2}}{J} \Omega_{m e c}^{2}-\frac{f}{J} \Omega_{m e c}-\frac{1}{J} C_{e m}-$ $\dot{\Omega}_{m e c}^{r e f}=-k \varepsilon_{\Omega}(k>0) \Rightarrow \frac{1}{J} C_{e m}=\frac{K_{1} K_{2}}{J} \Omega_{m e c}^{2}-$ $\frac{f}{J} \Omega_{m e c}-\dot{\Omega}_{m e c}^{r e f}+k \varepsilon_{\Omega} \Rightarrow C_{e m}=K_{1} K_{2} \Omega_{m e c}^{2}-$ $f \Omega_{m e c}-J \dot{\Omega}_{m e c}^{r e f}+J k \varepsilon_{\Omega}$ (17). With this choice, we obtain: $\dot{v}\left(\varepsilon_{\Omega}\right)=-k \varepsilon_{\Omega}^{2} \leq 0$. By neglecting losses, the electrical power produced by the generator is given by:

$$
P_{e}=C_{e m} \Omega_{m e c}
$$

\section{OPTIMIZATION WITH GENETIC ALGORITHMS}

If we apply the command $C_{e m}$ while keeping the pitch angle $(\beta)$ null, we can never limit the power at its nominal value, hence the necessity to optimize $\beta$. The optimization by a genetic algorithm [14] of $\beta$ from equation (3) will stabilize $C_{e m}$, which brings us to obtain a nearly constant electric power around its nominal value.

\section{Simulation Results}

$300 \mathrm{KW}$ wind turbine is used in simulation. The numerical values are given in Tab. 1.

The wind speed is comprised between $12.7 \mathrm{~m} / \mathrm{s}$ and 19.2 $\mathrm{m} / \mathrm{s}$ (fig.02), the rated speed is $12 \mathrm{~m} / \mathrm{s}$. The nominal value of the generator speed is $159.6857 \mathrm{rad} / \mathrm{s}$ and $0^{\circ}<\beta<90^{\circ}$. The aim of controlling is to limit the electrical power to 300 $K W$.

In fig. 3 we present the not optimized pitch angle. In fig.4, the pitch angle $(\beta)$ optimized with the genetic algorithm is presented.

TAB. 1. PARAMETERS OF WIND TURBINE WITH THREE BLADES

\begin{tabular}{|c|c|c|c|}
\hline Parameters & $R_{s}(\Omega)$ & $R_{r}(\Omega)$ & $L_{s}(H)$ \\
\hline $\begin{array}{c}\text { Numerical } \\
\text { value }\end{array}$ & 0.0063 & 0.0048 & 0.0118 \\
\hline $\begin{array}{c}\text { Parameters } \\
\text { Numerical } \\
\text { value }\end{array}$ & $L_{r}(H)$ & $L_{m}(H)$ & $P$ \\
\hline $\begin{array}{c}\text { Parameters } \\
\text { Generations }\end{array}$ & $\begin{array}{c}\text { Mutation } \\
\text { probability }\end{array}$ & $J\left(K g . m^{2}\right)$ \\
\hline $\begin{array}{c}\text { Numerical } \\
\text { value }\end{array}$ & 20 & $5 \%$ & 50 \\
\hline $\begin{array}{c}\text { Parameters } \\
\text { Numerical } \\
\text { value }\end{array}$ & $f$ & $R(m)$ & $G$ \\
\hline $\begin{array}{c}\text { Parameters } \\
\text { Numerical } \\
\text { value }\end{array}$ & 1.22 & 14 & 23 \\
\hline
\end{tabular}




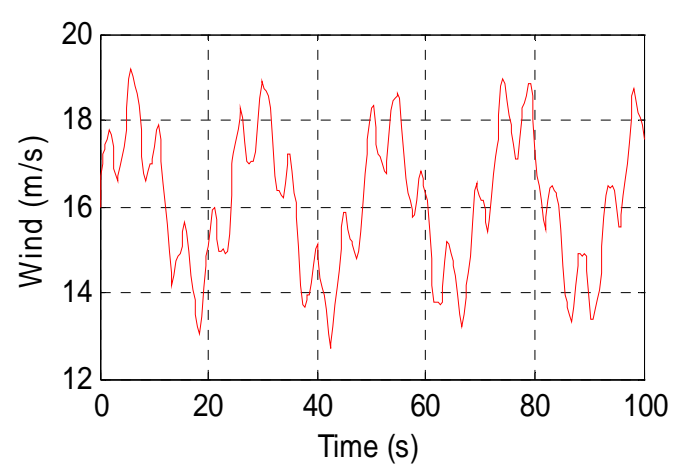

Figure.2. Wind profile.

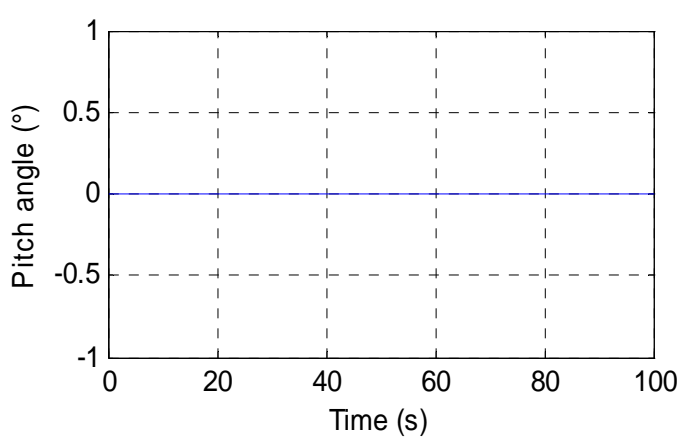

Figure.3. Pitch angle not optimized.

In fig.5 and fig.6, the tip speed ratio $(\lambda)$ does not exceed the optimal value ( $\lambda_{\text {opt }}=8.1$ ), which is normal. It is not affected by the pitch angle change; we obtained almost the same result with and without optimization of $\beta$ (fig.4).

In fig.07 the power coefficient exceeds its maximum value $\left(C_{p}^{\max }=0.4745\right)$, which is unacceptable. By optimizing the pitch angle with genetic algorithms, the power coefficient is optimized below its maximum (fig.8).

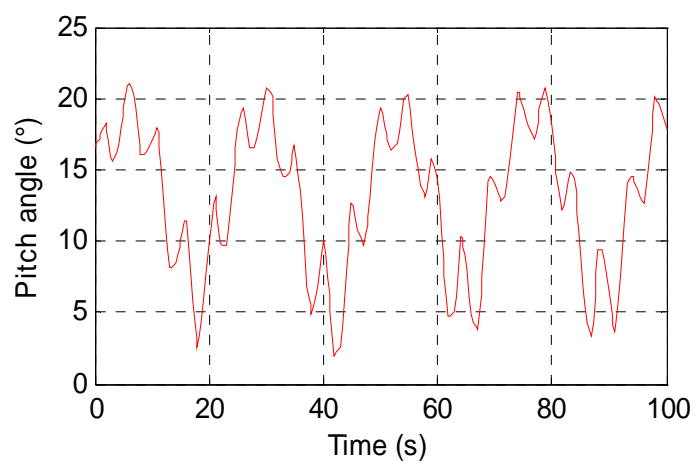

Figure.4. Pitch angle optimized with GA.

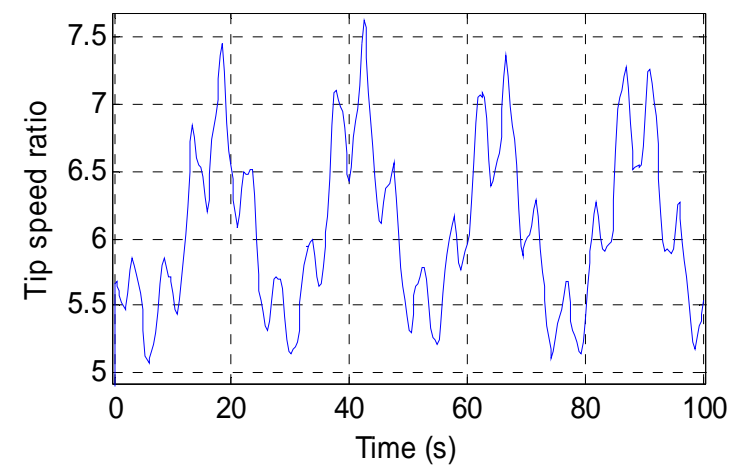

Figure.5. Tip speed ratio without pitch angle optimization.

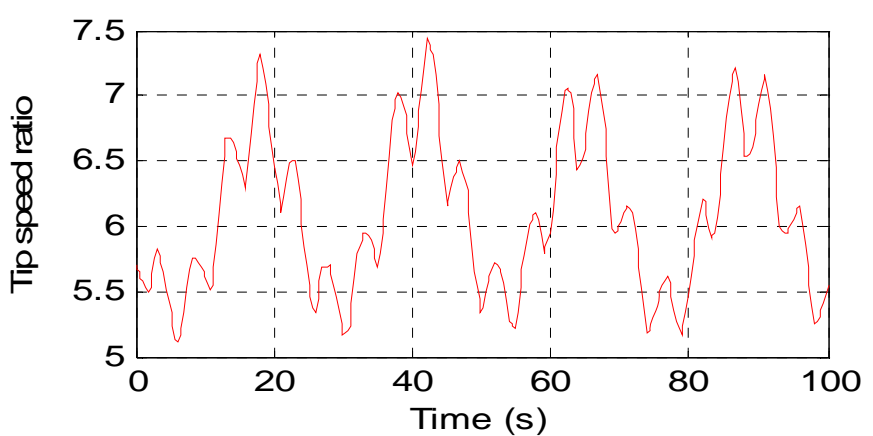

Figure.6. Tip speed ratio with pitch angle optimization.

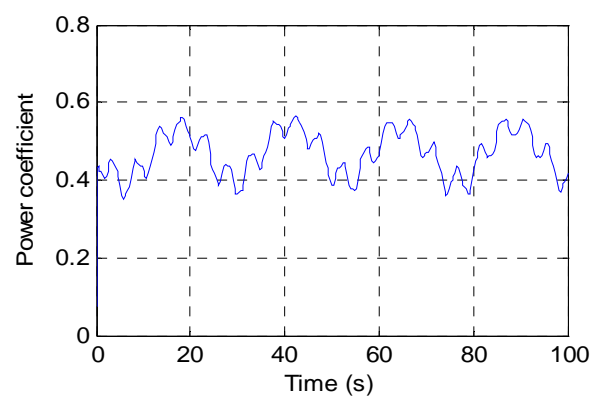

Figure.7. Power coefficient without pitch angle

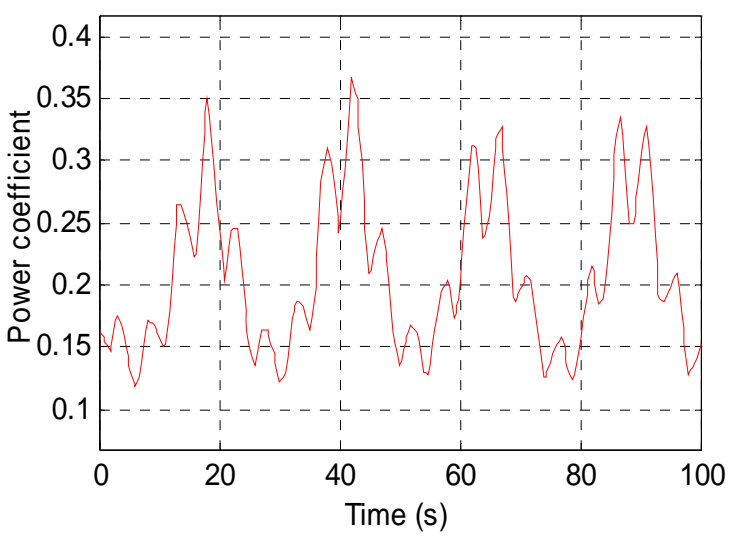

Figure.8. Power coefficient with pitch angle optimization. 


\section{CONCLUSION}

In this paper, the problem of variable speed wind turbine was discussed. The command of the generator was designed to limit the electrical power produced. The backstepping technique is used to design the command (Electromagnetic torque) that will be used to follow the reference generator speed. The power obtained does not represent the desired one, because in the steady state the electromagnetic torque presents large variations. Subsequently, the use of a genetic algorithm to optimize the pitch angle has yielded a couple with small variations (compared to the first case) in the steady state. And the final results, an electrical power that stabilizes around its nominal value.

\section{REFERENCES}

[1] S. Muller, M. Deicke, R.W. De Doncker, Doubly fed induction generator systems for wind turbines, IEEE Ind Appl Mag, 8 (2002), pp. 26-33

[2] L.M. Fernandez, C.A. Garcia, F. Jurado, Comparative study on the performance of control systems for doubly fed induction generator (DFIG) wind turbines operating with power regulation, Energy, Volume 33, Issue 9, pp. 1438-1452, 2008

[3] F.D. Bianchi, R.J. Mantz, C.F. Christiansen. Power regulation in pitch-controlled variable speed WECS above rated wind speed. Renewable Energy 29 (2004) 1911-1922.

[4] B. Boukhezzar, L. Lupua, H. Siguerdidjane, M. Hand. Multivariable control strategy for variable speed, variable pitche wind turbines. Renewable Energy 32 (2007) 1273-1287.
[5] Ahmet Serdar Yilmaz, Zafer Özer. Pitch angle control in wind turbines above the rated wind speed by multi-layer perceptron and radial basis function neural networks. Expert Systems with Applications 36 (2009) 9767-9775.

[6] S. Bououden, M. Chadli, S. Filali, A. El Hajjaji. Fuzzy model based multivariable predictive control of a variable speed wind turbine: LMI approach. Renewable Energy 37 (2012) 434e439.

[7] H. Camblong. Digital robust control of a variable speed pitch regulated wind turbine for above rated wind speeds. Control Engineering Practice 16 (2008) 946-958.

[8] Nesmat ABU-TABAK. « Stabilité dynamique des systèmes électriques multimachines : modélisation, commande, observation et simulation ». Thèse de doctorat. École centrale de Lyon. Le 19 Novembre 2008.

[9] X. Zheng, L. Li, D. Xu , J. Platts, Sliding mode MPPT control of variable speed wind power system, Power and Energy Engineering Conference, pp. 1-4, APPEEC 2009.

[10] S.M.Barakati,M.Kazerani, andX.Chen, "Anewwind turbine generation system based on matrix converter," in Proc. IEEE/PES General Meeting, Jun. 2005, vol. 3, pp. 2083-2089.

[11] Slootweg JG, De Haan SW, Polinder H, Kling WL. General model for representing variable speed wind turbines in power system dynamics simulations. IEEE Transactions on Power Systems 2003;18(1):144e51.

[12] Salma EL AIMANI « Modélisation de différentes technologies d'éoliennes intégrées dans un réseaux de moyenne tension ». Thèse de Doctorat. Université de Lille, France. Le 06 Décembre 2004.

[13] F. Farivar, M. A. Shoorehdeli, M.A. Nekoui, M. Teshnehlab, Chaos control and modified projective synchronization of unknown heavy symmetric chaotic gyroscope systems via Gaussian radial basis adaptive backstepping control, Nonlinear Dyn. 67 (2012) 1913-1941.

[14] David E. Goldberg. Genetic Algorithms in Search, Optimization, and Machine Learning. Addison-Wesley, Reading, Massachusetts, 1989 